\title{
Red wine-dependent reduction of nitrite to nitric oxide in the stomach
}

\author{
Bruno Gago ${ }^{\text {a }}$, Jon O. Lundberg ${ }^{\text {b }}$, Rui M. Barbosa ${ }^{\text {a, }}$, João Laranjinhaa ${ }^{\text {a,* }}$ \\ ${ }^{a}$ Center for Neuroscience and Cell Biology and Faculty of Pharmacy, University of Coimbra, 3000 Coimbra, Portugal \\ ${ }^{\mathrm{b}}$ Department of Physiology and Pharmacology, Karolinska Institutet, 17177 Stockholm, Sweden
}

Received 28 February 2007; revised 15 May 2007; accepted 4 June 2007

Available online 13 June 2007

\begin{abstract}
Nitrite may be a source for nitric oxide ( $\left.{ }^{\circ} \mathrm{NO}\right)$, particularly in highly acidic environments, such as the stomach. Diet products contribute also with reductants that dramatically increase the production of ${ }^{\bullet} \mathrm{NO}$ from nitrite. Red wine has been attributed health promoting properties largely on basis of the reductive antioxidant properties of its polyphenolic fraction. We show in vitro that wine, wine anthocyanin fraction and wine catechol (caffeic acid) dose- and $\mathrm{pH}$-dependently promote the formation of ${ }^{\bullet} \mathrm{NO}$ when mixed with nitrite, as measured electrochemically. The production of ${ }^{-} \mathrm{NO}$ promoted by wine from nitrite was substantiated in vivo in healthy volunteers by measuring ${ }^{\circ} \mathrm{NO}$ in the air expelled from the stomach, following consumption of wine, as measured by chemiluminescence. Mechanistically, the reaction involves the univalent reduction of nitrite, as suggested by the formation of ${ }^{\bullet} \mathrm{NO}$ and by the appearance of EPR spectra assigned to wine phenolic radicals. Ascorbic and caffeic acids cooperate in the reduction of nitrite to ${ }^{*} \mathrm{NO}$. Moreover, reduction of nitrite is critically dependent on the phenolic structure and nitro-derivatives of phenols are also formed, as suggested by caffeic acid UV spectral modifications. The reduction of nitrite may reveal previously unrecognized physiologic effects of red wine in connection with ${ }^{\circ} \mathrm{NO}$ bioactivity.
\end{abstract}

(C) 2007 Elsevier Inc. All rights reserved.

Keywords: Red wine; Nitrite; Nitric oxide; Phenolic compounds; Stomach; Diet; Free radicals

\section{Introduction}

Nitric oxide $\left({ }^{\circ} \mathrm{NO}\right)$, an endogenous diffusible free radical, is an important mediator in a wide range of physiological and pathological events. 'NO is produced in vivo by several isoforms of nitric oxide synthase (NOS), either constitutively or inducibly expressed (for review see ref. [1]). Independently of NOS, accumulating evidence suggest that heme proteins, xanthine oxidoreductase and thiol-containing enzymes may convert nitrite into ${ }^{\circ} \mathrm{NO}$ [2] during ischemic or hypoxic events [3-5]. These observations, among others showing that nitrite may regulate cell functions via protein modifications at heme and sulfhydryl sites, have spot nitrite as an endogenous molecule involved in the physiology and therapeutics of the cardiovascular system [6]. In particular, the chemical reduction of inorganic nitrite to ${ }^{*} \mathrm{NO}$ has been initially uncovered as a new biologically-relevant mechanism in acidic environments,

\footnotetext{
* Corresponding author. Fax: +351 239852569 .

E-mail address: laranjin@ci.uc.pt (J. Laranjinha).
}

notably the gastric compartment $[7,8]$. In the body, nitrite derives from nutritional sources, from reduction of ingested nitrate by commensal bacteria and from oxidation of endogenous ${ }^{\circ} \mathrm{NO}$ [9]. Major dietary sources of nitrite include cured meat and cereals but about $90 \%$ of ingested nitrite by humans is accounted for by the reduction of nitrate (present in high content in green leafy vegetables such as lettuce and spinach) in the oral cavity via the action of nitrate reductase expressed by microorganisms present in the surface of the mouth [10-12]. Ingested nitrate is readily absorbed in the upper small intestine [13] and equilibrates with body fluids but $25 \%$ is actively secreted by the salivary glands back to the mouth [14].

At the acidic $\mathrm{pH}$ of the stomach, nitrite yields ${ }^{\circ} \mathrm{NO}$ and NOderived species that locally may have biological impact in terms of antimicrobial effects, blood flow, mucus secretion and gastric motility (for review see ref. [15]). At the gastric $\mathrm{pH}$ nitrite exists in a complex equilibrium with nitrous acid and several reactive nitrogen oxides (reactions $1-5$ ). When taking place in the liquid phase of the stomach, because the chemical system is not closed, it is expected that ${ }^{\circ} \mathrm{NO}$ due to its limited 
solubility in water will leave the aqueous phase being present in the expelled air.

$\mathrm{NO}_{2}^{-}+\mathrm{H}^{+} \leftrightarrows \mathrm{HNO}_{2}$

$2 \mathrm{HNO}_{2} \leftrightarrows^{\bullet} \mathrm{NO}+{ }^{\bullet} \mathrm{NO}_{2}+\mathrm{H}_{2} \mathrm{O}$

$\cdot \mathrm{NO}+{ }^{\cdot} \mathrm{NO}_{2} \leftrightarrows \mathrm{N}_{2} \mathrm{O}_{3}$

$\mathrm{N}_{2} \mathrm{O}_{3}+\mathrm{H}_{2} \mathrm{O} \leftrightarrows 2 \mathrm{HNO}_{2}$

$4^{\bullet} \mathrm{NO}+\mathrm{O}_{2}+2 \mathrm{H}_{2} \mathrm{O} \leftrightarrows 4 \mathrm{NO}_{2}^{-}+4 \mathrm{H}^{+}$

Whereas the production of ${ }^{\bullet} \mathrm{NO}$ via reactions 1 and 2 may occur at low fluxes, it can be envisage that the production of ${ }^{\circ} \mathrm{NO}$ from acidic nitrite in the stomach can be dramatically enhanced, providing that compounds endowed with adequate thermodynamic and kinetic properties are available to univalently reduce nitrite. Ascorbic acid, exhibiting a low redox potential $(0.28 \mathrm{~V})$ and actively secreted in the gastric juice is an obvious candidate $[16,17]$. Yet, dietary polyphenols that, depending on its structure, have been shown to redox interact with oxidant radicals, thus preventing oxidative reactions, may be present in large amounts in the stomach in a diet-dependent way and likely promote ${ }^{\circ} \mathrm{NO}$ formation at high fluxes. Accordingly, it has been demonstrated that chlorogenic acid and quercetin enhance the production of ${ }^{*} \mathrm{NO}$ from nitrite at acidic $\mathrm{pH}[18,19]$.

Red wine is a beverage with a high content in polyphenols, comprising flavonoids and nonflavonoid compounds [20] known for its ability to reduce a variety of oxidant free radicals, thus acting as antioxidants [21]. Further considering that wine polyphenols may be abundantly found in the stomach it is likely that at this location may interact with nitrite yielding ${ }^{\circ} \mathrm{NO}$. We aimed at ascertaining the potential activity of red wine as a catalyst of -NO formation in the stomach in vivo in healthy volunteers and establish the mechanism of such interaction in in vitro experiments. On basis of electrochemical, chemiluminescence, UV and electron paramagnetic resonance (EPR) spectroscopies, data suggest that ingestion of red wine is associated with an increase of ${ }^{-} \mathrm{NO}$ in the stomach. The mechanism of ${ }^{-} \mathrm{NO}$ formation involves the one-electron reduction of nitrite, a phenomenon dependent on the structure of phenols present in the wine and that is cooperative with physiological nitrite reductants, namely ascorbic acid. In addition to oxidation, nitrosation and nitration of the phenols may also occur. Of significance, these results establish a new pathway for the known impact of wine consumption in human health by way of NO-dependent physiological and pathophysiological events, at least in the gastric compartment.

\section{Materials and methods}

\section{Chemicals and wine}

Caffeic (3,4-Dihydroxycinnamic acid), p-coumaric (4-Hydroxycinnamic acid) and ascorbic acids were purchased from Fluka
Biochemika. Solid sodium nitrite $\left(\mathrm{NaNO}_{2}\right)$ and sodium nitrate $\left(\mathrm{NaNO}_{2}\right)$ were purchased from Merck. Portuguese red wine was from Douro region (1997). All other chemicals were of analytical grade.

\section{Nitric oxide measurement}

In in vitro experiments ${ }^{\mathrm{NO}}$ was measured electrochemically using the ISO-NO Mark II ${ }^{*} \mathrm{NO}$ meter and sensor (World Precision Instruments, LTD, Hertfordshire, UK). The electrode was calibrated in $\mathrm{KI}-\mathrm{H}_{2} \mathrm{SO}_{4}(0.1 \mathrm{M})$ with stock solutions of nitrite, according to the manufacturer.

In in vivo experiments ${ }^{\circ} \mathrm{NO}$ was measured in the expelled air from stomach using a chemiluminescence analyzer (Aerocrine $\mathrm{AB}$, Stockholm, Sweden). The instrument's detection limit for -NO was $1 \mathrm{ppb}$. Calibration of the instrument was performed with 'NO gas (10 ppm ${ }^{\circ} \mathrm{NO}$ in nitrogen; AGA AB, Lidingö, Sweden).

\section{Production of nitric oxide from nitrite at low $\mathrm{pH}$ in vitro}

Stock solutions of caffeic, $p$-coumaric and ascorbic acids were prepared daily in ultra pure water saturated with argon. The solutions were protected from light under an argon atmosphere, at room temperature.

A phenolic wine extract was prepared according to previously described methodologies [22,23] with some changes. Briefly, dealcoholized wine was applied to a column Sep-Pak $\mathrm{C}_{18}, 10 \mathrm{~g}$ (Waters) previously conditioned with methanol $5 \mathrm{ml} / \mathrm{min}$ for $20 \mathrm{~min}$ followed by water:formic acid (95:5) $5 \mathrm{ml} / \mathrm{min}$ for additional $20 \mathrm{~min}$. A first fraction was eluted with water:formic acid (95:5) $2 \mathrm{ml} / \mathrm{min}$ for 4 hours and, afterwards, a second fraction, consisting of anthocyanins was eluted with a mixture water:acetonitrile:formic acid (65:30:5) $2 \mathrm{ml} / \mathrm{min}$ for $40 \mathrm{~min}$. The fractions were concentrated by evaporation under reduced pressure at $45^{\circ} \mathrm{C}$ to the original volume of red wine.

Caffeic acid, $p$-coumaric acid, ascorbic acid, red wine and anthocyanin extract from red wine, were assayed for nitrite reducing ability. Nitrite was added at time 0 to a solution of each compound tested at the defined $\mathrm{pH}$. The assays were performed in simulated gastric juice (SGJ) prepared according to the United States Pharmacopeia (Vol. 25) without pepsin. In all the experiments $\mathrm{pH}$ was rigorously controlled before the addition of nitrite.

\section{in vivo studies}

Three healthy fasting volunteers consumed $125 \mathrm{ml}$ of red wine following ingestion of a solution of $5 \mathrm{mg}$ sodium nitrate/ $\mathrm{kg}$ body weight in $100 \mathrm{ml}$ of water to simulate intake of nitratecontaining green vegetables, according to previously described and safely established conditions $[24,25]$. ${ }^{\circ} \mathrm{NO}$ was measured in the expelled air from the stomach sequentially at different times according to the following plan: 1) under fasting conditions, 2) ingestion of nitrate solution and measurement 45 min later to permit absorption and secretion of nitrate in 
saliva from plasma, 3) ingestion of red wine and measurements 15 and $30 \mathrm{~min}$ later. The air expelled from the stomach was collected into gas-tight bags by voluntary regurgitation at the different times and ${ }^{\circ} \mathrm{NO}$ concentrations were determine by chemiluminescence [24].

\section{Spectrophotometric measurements}

Caffeic acid spectral modifications were followed between 230 to $450 \mathrm{~nm}$ by recording a spectrum every $3 \mathrm{~min}$ during 2 hours, following the addition of nitrite in a Lambda $45 \mathrm{UV} /$ VIS spectrophotometer (Perkin-Elmer Ltd., UK). The time course of caffeic acid oxidation was followed by the decrease in the absorbance at $310 \mathrm{~nm}$ in a Lambda 6 UV/VIS spectrophotometer (Perkin-Elmer Ltd, UK) at room temperature in the presence of $\mathrm{O}_{2}$. Nitrite was added at time 0 and left to react with caffeic acid for $25 \mathrm{~min}$.

\section{EPR measurements}

EPR spectra were recorded with a Bruker EMX spectrometer at room temperature in a continuous-flow system using open Pasteur pipette (or the Aqua X cell from Bruker) inserted in the EPR cavity and directly connected to a 1-ml mixing cell.

In the case of caffeic acid, its mixture with nitrite contained $200 \mathrm{mM} \mathrm{Mg}^{2+}$ and in some experiments the mixture was added of $50 \mathrm{mM} \mathrm{NaOH}$ in a second mixing cell, before being pumped ( $8 \mathrm{ml} / \mathrm{min}$ ) to the cavity, in order to stabilize the semiquinone radical. Appropriate controls without nitrite were run in order to subtract the contribution of caffeic acid autoxidation at the alkaline $\mathrm{pH}$.

The instrument settings for caffeic and ascorbic acid mixtures with nitrite $(1: 1)$ were: microwave frequency, $9.7 \mathrm{GHz}$, microwave power, $20 \mathrm{~mW}$, modulation amplitude, $1 \mathrm{G}$; time constant, $0.65 \mathrm{~s}$.

For the measurement of radicals in wine, the beverage was mixed (1:1) with a solution of $4 \mathrm{mM}$ nitrite in a mixing cell located before the cavity. The instruments settings were as before except that modulation amplitude was $2 \mathrm{G}$ and time constant $20 \mathrm{~ms}$.

\section{Results}

Production of nitric oxide from nitrite promoted by red wine in vitro

Fig. 1A shows the time course of ${ }^{-N O}$ production from $10 \mu \mathrm{M}$ nitrite, at $\mathrm{pH} 2.0$ and $\mathrm{pH} 1.5$ in the presence of red wine added at different dilutions and under normal atmosphere. The weakest the dilution of the wine, highest the production of ${ }^{\bullet} \mathrm{NO}$, as shown in Fig. 1B. It is apparent that $5.8 \pm 0.2$ and $8.0 \pm 0.1 \mu \mathrm{M}$ $\cdot \mathrm{NO}$ is maximally produced at $\mathrm{pH} 2$ and 1.5 , respectively, in the presence of a 10 fold dilution of the wine (Fig. 1A, lines 4), being $0.8 \pm 0.0$ and $1.2 \pm 0.0 \mu \mathrm{M}$ for a 1000 fold dilution (Fig. 1A, lines 2). Ten fold is the expected dilution of wine in the stomach following an intake of a $80 \mathrm{ml}$ glass after a full meal [26,27].
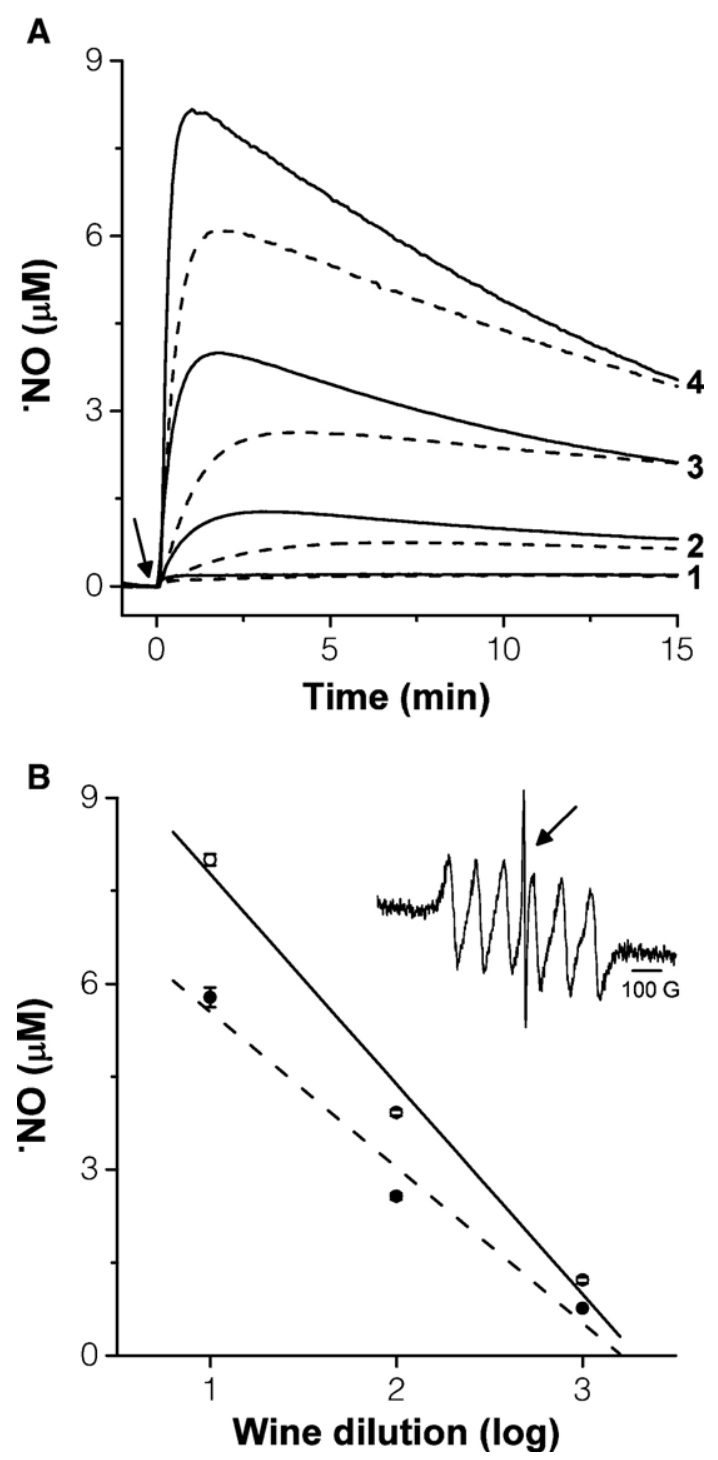

Fig. 1. Production of ${ }^{\bullet} \mathrm{NO}$ from nitrite in the presence of different dilutions of red wine at $\mathrm{pH} 1.5(-)$ and $\mathrm{pH} 2.0$ (- - -). (A) Time courses of ${ }^{\circ} \mathrm{NO}$ production upon addition of $10 \mu \mathrm{M}$ nitrite (arrow) in the absence (lines 1 ) and in the presence of red wine diluted 1000 (lines 2), 100 (lines 3) and 10 fold (lines 4). (B) Peak of 'NO concentration at pH 1.5 (-) and pH 2.0 (- - -) versus wine dilution. Inset: wine free radical (arrow), sitting in the middle of the $\mathrm{Mn}^{2+}$ spectrum, obtained upon mixing wine with nitrite solution in a mixing cell before being pumped to EPR cavity. In (B) values are means $\pm \operatorname{SEM}(n=3)$.

The total amount of $\cdot \mathrm{NO}$ produced is dependent on the $\mathrm{pH}$; for instance, a 100 fold dilution of red wine corresponds to a decrease of $44.6 \pm 1.1 \%$ and $48.9 \pm 0.2 \%$ in the maximal production of ${ }^{\circ} \mathrm{NO}$ for $\mathrm{pH} 2.0$ and 1.5 respectively (Fig. 1B). When the wine is diluted ten fold, the addition of nitrite induces a peak of $\cdot \mathrm{NO}$ at the $2.0 \pm 0.0 \mathrm{~min}$ and $1.1 \pm 0.0 \mathrm{~min}$ for $\mathrm{pH} 2.0$ and $\mathrm{pH} 1.5$, respectively. That is, the $\mathrm{pH}$ and the dilution of wine also affect the initial rate of ${ }^{\circ} \mathrm{NO}$ production (not shown). The rate increases when: a) the $\mathrm{pH}$ decreases and b) the concentration of wine increases.

At $\mathrm{pH} 7.4$ the wine-dependent production of ${ }^{\circ} \mathrm{NO}$ is meaningless (not shown). 
Inset in Fig. 1B shows the wine free radical (arrow), obtained upon mixing the wine with nitrite solution, sitting in the middle of the $\mathrm{Mn}^{2+}$ spectrum found in the wine. The wine signal is ascribed to its phenolic fraction [28].

\section{Production of nitric oxide from nitrite promoted by red wine} in vivo

Fig. 2 shows the content of ${ }^{\circ} \mathrm{NO}$ in the expelled air from the stomach of fasting volunteers consuming nitrate and red wine. The controlled ingestion of nitrate to simulate the consumption of green vegetables $[24,25]$ permitted to detect 45 min later an increase of ${ }^{*} \mathrm{NO}(12133 \pm 1067 \mathrm{ppb})$ in the air, as compared with fasting conditions $(1196 \pm 571 \mathrm{ppb})$. This is the time required to establish maximum salivary nitrite, following the enterosalivary recirculation of nitrate and its reduction to nitrite by mouth commensal bacteria [25]. Following consumption of wine the ${ }^{-} \mathrm{NO}$ in the air expelled from the stomach peaks at $15 \mathrm{~min}(30215 \pm 4399 \mathrm{ppb})$, decreasing afterwards $(30 \mathrm{~min}$, $20638 \pm 4939 \mathrm{ppb})$.

In the absence of exogenous nitrate consumption the total amount of ${ }^{*} \mathrm{NO}$ produced by wine consumption was less than $20 \%$ as compared with nitrate plus wine (not shown).

\section{Production of nitric oxide from nitrite promoted by red wine phenolics in vitro}

Preliminary experiments have shown that relevant phenolic fractions obtained from the wine, namely the anthocyanins, exhibited the capacity to produce ${ }^{\circ} \mathrm{NO}$ from nitrite at low $\mathrm{pH}$
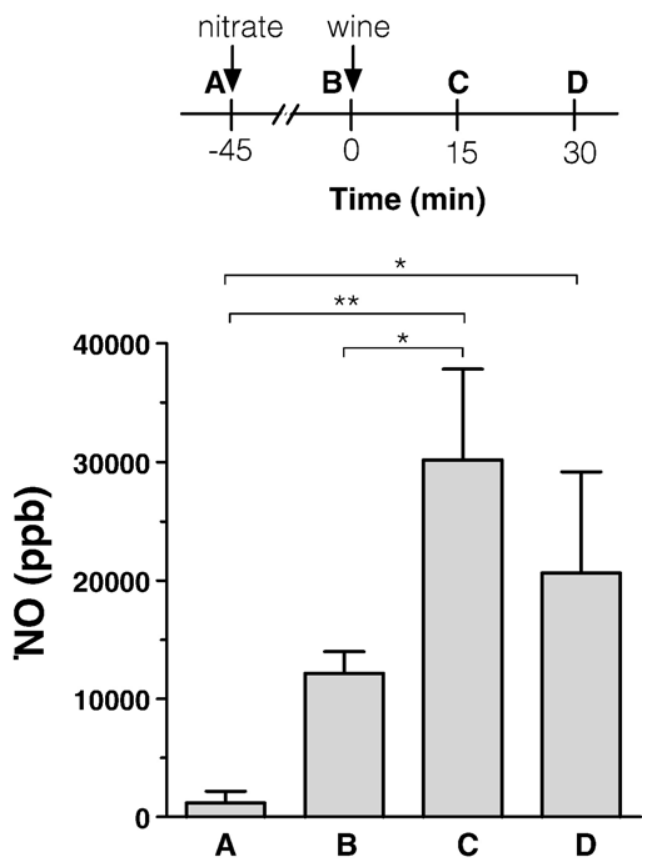

Fig. 2. In vivo peak ${ }^{\circ} \mathrm{NO}$ values (ppb) in expelled air from the stomach. Measurements where made at 4 time points. First after overnight fasting (A), then 45 minutes after drinking a solution of nitrate $5 \mathrm{mg} / \mathrm{kg}$ of body weight (B) and $15(\mathrm{C})$ and $30 \mathrm{~min}(\mathrm{D})$ after drinking $125 \mathrm{ml}$ of red wine. Values are means \pm SED $(n=3),{ }^{*} p<0.05,{ }^{* *} p<0.01$.
Table 1

Production of ${ }^{\bullet}$ NO from nitrite promoted by red wine anthocyanin fraction

\begin{tabular}{lll}
\hline Sample (10 fold dilution) & $\cdot$ NO Peak $(\mu \mathrm{M})$ & $\mathrm{T}_{80}(\mathrm{~s})$ \\
\hline Anthocyanin fraction & $6.60 \pm 0.20$ & $32.00 \pm 1.73$ \\
Red wine & $7.47 \pm 0.16$ & $33.33 \pm 2.33$ \\
Control $^{\text {a }}$ & $0.17 \pm 0.02$ & $11.67 \pm 1.76$ \\
\hline
\end{tabular}

Values are means $\pm \operatorname{SEM}(n=3)$.

${ }^{\text {a }}$ Without any phenol.

(Table 1). In order to mechanistically address the underlying reaction we have selected a wine catechol known for its reducing ability (caffeic acid) and the structurally related monophenol ( $p$-coumaric acid) [29].

Fig. $3 \mathrm{~A}$ shows the time course of ${ }^{-N O}$ production upon addition of $50 \mu \mathrm{M}$ nitrite to caffeic acid solutions (10, 25, 50, $100,200$ and $1000 \mu \mathrm{M})$ at $\mathrm{pH} 2.0$. Within the range of the caffeic acid concentrations tested, the production of ${ }^{\circ} \mathrm{NO}$ increases with the concentration of the wine phenolic compound. The maximal production of $\mathrm{NO}$ occurs $0.6 \mathrm{~min}$ after the addition of nitrite, peaking at approx. $11.5 \mu \mathrm{M}$ for $1000 \mu \mathrm{M}$ caffeic acid. Also, the production of ${ }^{\bullet} \mathrm{NO}$ increases with the concentration of nitrite (Fig. 3B). However, whereas the rate of $\mathrm{NO}$ decay is insensitive to the concentration of nitrite (Fig. 3B), the concentration of caffeic acid affects the rate of ${ }^{\circ} \mathrm{NO}$ decay (Fig. 3A); the higher the concentration, the faster the decay, thus suggesting that ${ }^{\circ} \mathrm{NO}$ and $\mathrm{NO}$-derived species may further react with the phenolic acid. For instance, for $1000 \mu \mathrm{M}$ caffeic acid, ${ }^{\circ} \mathrm{NO}$ decays $50 \%$ in approx. $2.6 \mathrm{~min}$, but it takes $15 \mathrm{~min}$ to decay by approx. $30 \%$ in the presence of $10 \mu \mathrm{M}$ caffeic acid.

Fig. $3 \mathrm{~A}$ also shows that, at the stomach $\mathrm{pH}$, in the absence of the wine phenolic compound the decomposition of $\mathrm{HNO}_{2}$ yielding the production of $\mathrm{NO}$ (line 1) is negligible as compared with that promoted by caffeic acid (lines 2-7).

The monophenolic analogue of caffeic acid, $p$-coumaric acid, under the same experimental conditions, induced ${ }^{\circ} \mathrm{NO}$ production at concentrations one order magnitude lower than those obtained with caffeic acid (Fig. 3C). The addition of $50 \mu \mathrm{M}$ nitrite to $1000 \mu \mathrm{M} p$-coumaric acid resulted in approx. $0.5 \mu \mathrm{M} \cdot \mathrm{NO}$ (Fig. 3C, line 3) and, for the same concentration of caffeic acid, a peak of approx. $11.5 \mu \mathrm{M} \cdot \mathrm{NO}$ was observed (Fig. $3 \mathrm{~A}$, line 7 ). In fact, the ${ }^{\circ} \mathrm{NO}$ levels obtained with $p$-coumaric are not significantly different from those obtained by the spontaneous decomposition of $\mathrm{HNO}_{2}$ to ${ }^{\circ} \mathrm{NO}$ (Fig. 3A, line 1).

\section{Combined effect of ascorbic and caffeic acids on nitric oxide production in vitro}

Ascorbic acid is actively secreted in the stomach $[17,30]$ and has the capacity to reduce $\mathrm{HNO}_{2}$ to ${ }^{\circ} \mathrm{NO}$ and inhibit the local formation of N-nitrosamines [31,32]. Thus, caffeic acid and other wine phenols have to compete with ascorbic acid, an intrinsic reductant of gastric juice, for nitrite. A mixture of the phenolic and ascorbic acids was used to look for possible interactions in the production of ${ }^{\circ} \mathrm{NO}$.

Fig. 4 shows that the addition of $10 \mu \mathrm{M}$ nitrite to SGJ, devoid of pepsin at $\mathrm{pH} 2.0$ containing either $10 \mu \mathrm{M}$ of caffeic acid or 
$10 \mu \mathrm{M}$ ascorbic acid, resulted in a maximal production of approx. 0.8 (line 3) and $0.55 \mu \mathrm{M} \cdot \mathrm{NO}$ (line 2), respectively. When nitrite is added to a mixture of $10 \mu \mathrm{M}$ caffeic acid and
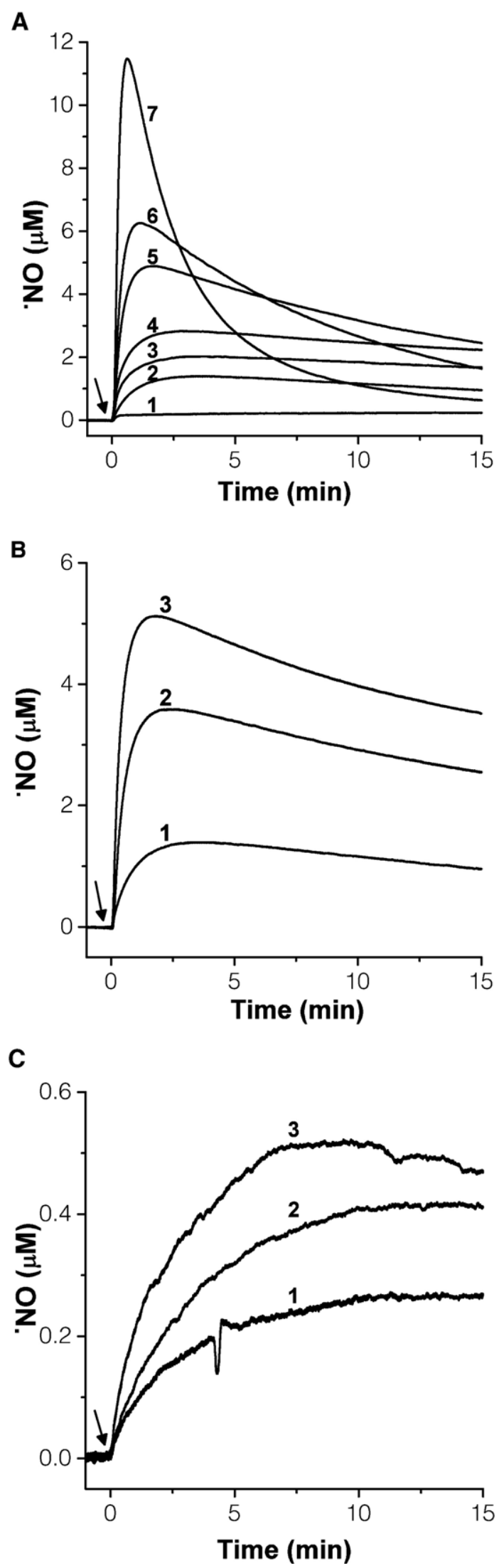

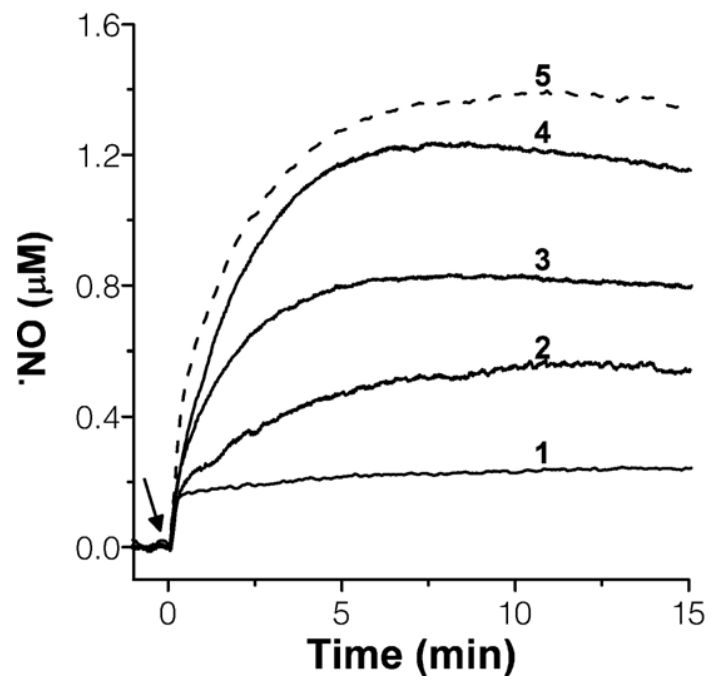

Fig. 4. Time courses of ${ }^{\circ} \mathrm{NO}$ production from nitrite in the presence of caffeic acid and ascorbic acid at $\mathrm{pH} 2.0$. $\mathrm{NO}$ production upon addition (arrow) of $10 \mu \mathrm{M}$ nitrite in the absence (line 1), and in the presence of $10 \mu \mathrm{M}$ ascorbic acid (line 2), $10 \mu \mathrm{M}$ caffeic acid (line 3 ), $10 \mu \mathrm{M}$ ascorbic acid plus $10 \mu \mathrm{M}$ caffeic acid (line 4). Line 5 corresponds to the mathematical sum of lines 2 and 3.

$10 \mu \mathrm{M}$ ascorbic acid the maximal production of ${ }^{\circ} \mathrm{NO}$ is approx. $1.25 \mu \mathrm{M}$ (line 4), that is, an effect similar to the sum of the effects of caffeic acid and ascorbic acid (line 5), suggesting that, for identical concentrations, the phenol efficiently competes with ascorbic acid and contributes independently for the production of ${ }^{*} \mathrm{NO}$.

\section{Structural modifications of ascorbic and caffeic acids monitored by EPR and UV spectroscopies.}

It has been reported that ascorbic acid $\left(\mathrm{pK}_{1}=4.1\right)$, upon interaction with nitrite, is oxidized to dehydroascorbate and intermediary radicals are expected to be formed $[7,17,32,33]$. Similarly to ascorbic acid, caffeic acid is known as an antioxidant which in view of its redox properties is capable to reduce several compounds, including vitamin E radical [34]. Considering that the reduction potential of nitrite $(\approx 0.9 \mathrm{~V})$ is higher than that of vitamin E radical $(0.48 \mathrm{~V})$, it is expected that the production of ${ }^{\cdot} \mathrm{NO}$ from nitrite involves a redox reaction, encompassing the univalent reduction of nitrite and the oxidation of caffeic acid to the corresponding $o$-semiquinone radical. EPR and UV spectroscopies allowed us to follow the formation of the one-electron oxidation intermediates and the stable products of caffeic acid upon reaction with nitrite, respectively (Fig. 5). Fig. 5A (line 2) shows the typical doublet spectra $(\mathrm{aH}=1.8 \mathrm{G})$ of ascorbate radical obtained by EPR under

Fig. 3. Time courses of ${ }^{\circ} \mathrm{NO}$ production from nitrite in the presence of caffeic acid and $p$-coumaric acid at $\mathrm{pH} \mathrm{2.0.} \mathrm{NO}$ production upon addition (arrow) of: (A) $50 \mu \mathrm{M}$ nitrite, in the absence (line 1) and in the presence of 10,25, 50, 100, 200 and $1000 \mu \mathrm{M}$ caffeic acid (lines 2 to 7, respectively); (B) 25, 50 and $100 \mu \mathrm{M}$ nitrite in the presence of $50 \mu \mathrm{M}$ caffeic acid (lines 1 to 3 , respectively); (C) $50 \mu \mathrm{M}$ nitrite, in the absence (line 1) and in the presence of 10 and $1000 \mu \mathrm{M}$ $p$-coumaric acid (lines 2 and 3, respectively). 
A

1
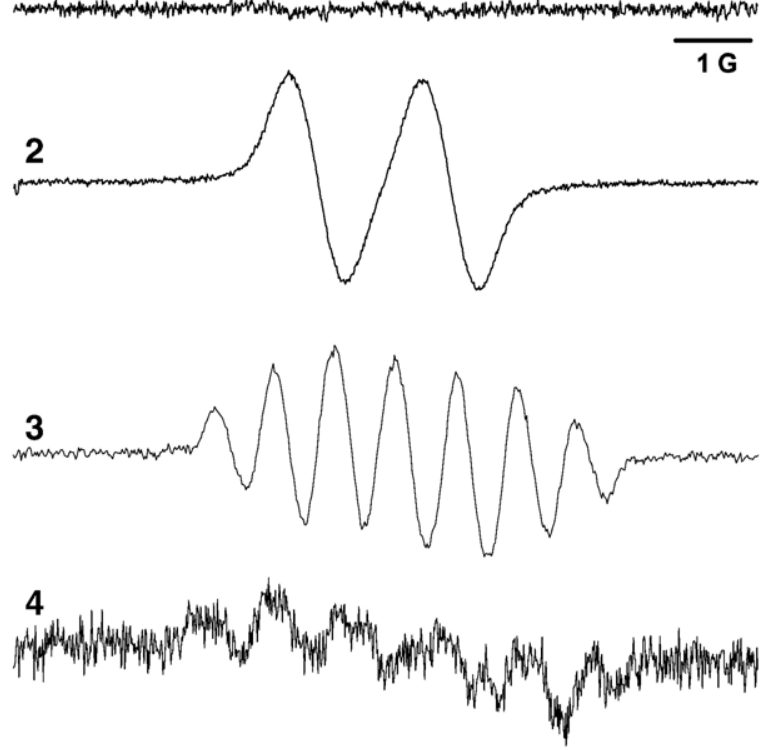

5

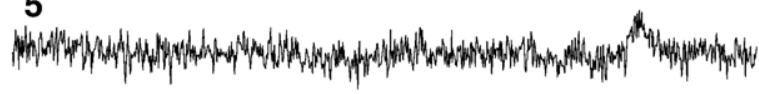

B

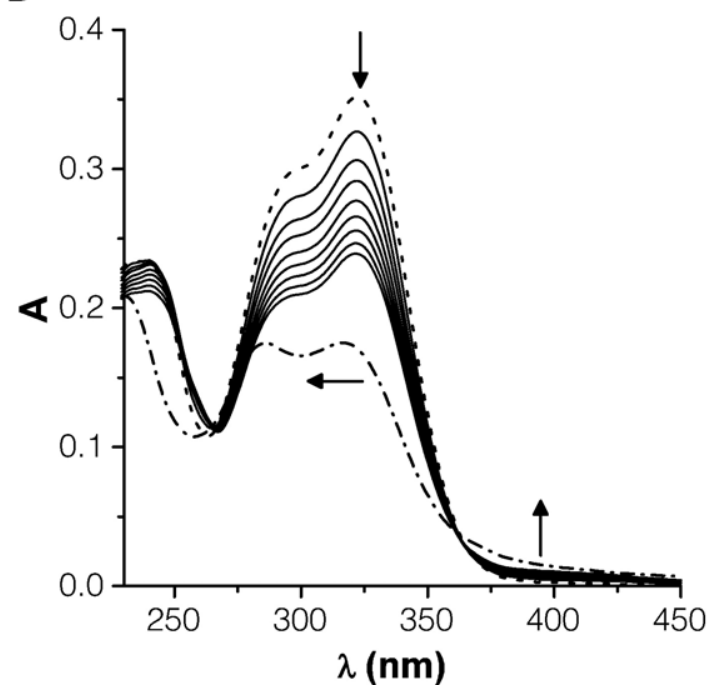

C

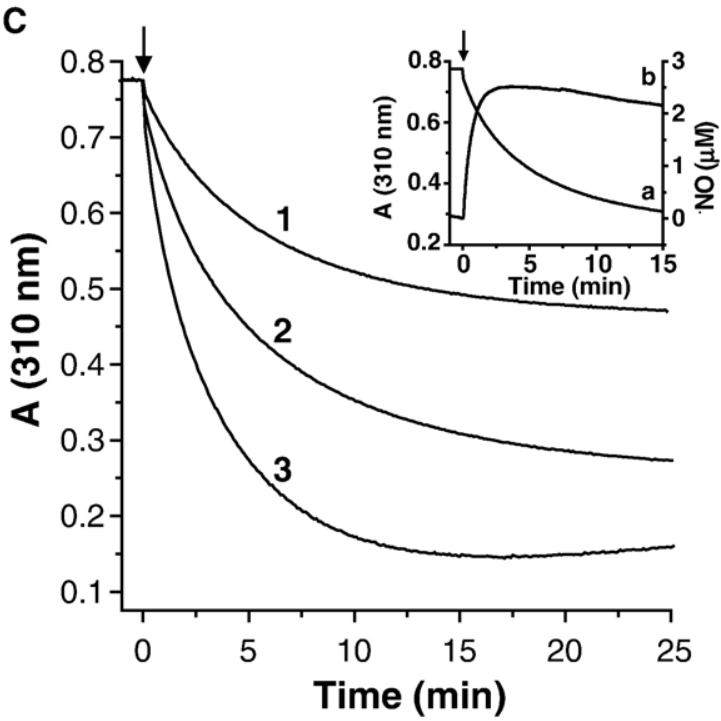

Fig. 5. EPR and UV spectral modifications of caffeic acid and ascorbic acid in the presence of nitrite. (A) EPR signal of ascorbate radical (line 2) and caffeic acid $o$-semiquinone radical (line 4) obtained under flow conditions upon mixing $2 \mathrm{mM}$ of the compounds with $4 \mathrm{mM}$ of nitrite at $\mathrm{pH} 2.0$. Line 1 is the control with the reductants but without nitrite and line 3 is the mixture of caffeic acid with nitrite alkalinized immediately before being pumped to the EPR cavity, as described under methods. Spectrum 3 is obtained by the difference between the spectrum of caffeic acid plus nitrite and caffeic acid alone, thus avoiding caffeic acid autoxidation at the alkaline $\mathrm{pH}$. The conditions for line 5 are identical to those of line 4 but without nitrite. EPR instrumental settings are as described under methods but sweep width and receiver gain were adjusted for plotting the spectra. (B) UV spectral changes of $25 \mu \mathrm{M}$ caffeic acid at $\mathrm{pH} 1.5$ during the reaction with $50 \mu \mathrm{M}$ nitrite: before addition of nitrite (- - ), every $3 \mathrm{~min}(-)$ and after 2 hours (- - - of incubation. Downward and upward arrows indicate decrease and increase in absorbance as the reaction proceeds. Leftward arrow indicates shifting to the left; (C) Time course of oxidation of $25 \mu \mathrm{M}$ caffeic acid at pH 1.5 followed by the decay in absorbance at $310 \mathrm{~nm}$ upon addition of 25, 50 and $100 \mu \mathrm{M}$ nitrite (lines 1 to 3, respectively). Inset: Relationship between oxidation of $25 \mu \mathrm{M}$ caffeic acid (line a) and ${ }^{\circ} \mathrm{NO}$ production (line b) upon addition of $50 \mu \mathrm{M}$ nitrite.

flow conditions $(8 \mathrm{ml} / \mathrm{min})$ of a mixture of ascorbic acid with nitrite at $\mathrm{pH} 2.0$ in a mixing cell. Likewise, Fig. 5A (lines 3 and 4) shows the EPR spectra assigned to caffeic acid $o$-semiquinone radical [34], the one-electron oxidation product of caffeic acid, obtained upon mixing the phenolic acid with nitrite. Caffeic acid was let to react with nitrite at $\mathrm{pH} 2.0$ in a mixing cell and then transferred to the cavity at a flow of $8 \mathrm{ml} / \mathrm{min}$ (line 4 ). In a second experiment and in an attempt to stabilize the radical, after the mixing at $\mathrm{pH} 2.0$ and just before reaching the EPR cavity, the reaction mixture was alkalinized. The EPR spectrum was then recorded and subtracted by that acquired in a control experiment under the same experimental conditions but in the absence of 
nitrite (i.e., autoxidation of caffeic acid at identical alkaline $\mathrm{pH}$ ). The resulting spectrum is shown in line 3 . The formation of the $o$-semiquinone radical, corresponding to the one-electron oxidation of the parent phenol is in accordance with results by others, showing the formation of chlorogenic and quercetin radicals upon reaction with acidic nitrite $[18,19]$.

The spectral changes of caffeic acid in the UV promoted by nitrite at $\mathrm{pH} 1.5$ are depicted in Fig. 5B. Upon the addition of $50 \mu \mathrm{M}$ nitrite to $25 \mu \mathrm{M}$ caffeic acid, the original phenolic spectrum (dashed line) suffered a decrease of absorbance intensity along the time (Fig. 5B). The spectral changes suggest the decay of the $o$-semiquinone radical to the corresponding $o$ quinone, for isosbestic points at 265 and $365 \mathrm{~nm}$ can be early noticed during the spectral transitions [29]. The rate of caffeic acid oxidation is dependent on the concentration of nitrite. This may be appreciated from the reaction time courses followed at $310 \mathrm{~nm}$ (Fig. 5C). Inset panel illustrates the relationship between $\mathrm{NO}$ production and caffeic acid oxidation followed at $310 \mathrm{~nm}$. It is also apparent from Fig. 5B that with time species other than the $o$-quinone accumulate, as the isosbestic points are missed. This conclusion can also be inferred from the increase in the absorbance at $310 \mathrm{~nm}$ (Fig. 5C, line 3) for later times of the reaction.

\section{Discussion}

The production of ${ }^{*} \mathrm{NO}$ independent of the ${ }^{*} \mathrm{NO}$ synthases has been reported under conditions of gastric acidity [24,35,36], in acidified urine [37], on the skin surface [38,39] and in the oral cavity [11]. This nonenzymatic production of ${ }^{*} \mathrm{NO}$ has been attributed to the chemical reduction of nitrite in acidic environments [7,8]. Under certain conditions of hypoxia, heme proteins (notably myoglobin and hemoglobin), xanthine oxidoreductase and thiol-containing enzymes may also favour the conversion of nitrite to ${ }^{\circ} \mathrm{NO}[2]$.

The acidic reduction encompasses, as the first step, the conversion of nitrite to $\mathrm{HNO}_{2}$. The relatively low $\mathrm{pKa}$ of nitrite (3.36) (reaction 1) narrows the physiological relevance for the reaction, being the stomach and ischemic tissues as the most likely environments for the acidic reduction of nitrite to ${ }^{*} \mathrm{NO}$. Accordingly, in 1994, Lundberg et al. [24] showed that following consumption of lettuce, a nitrate-rich vegetable (nitrate is reduced to nitrite in the mouth by local flora), by healthy subjects the levels of ${ }^{\bullet} \mathrm{NO}$ in the expelled air from their stomach were increased fourfold.

The second required step is the one-electron reduction. $\mathrm{HNO}_{2}$ exists in a complex equilibrium with $\mathrm{N}_{2} \mathrm{O}_{3}$ (reactions 2-4) [40]. However, in the presence of reductants, the equilibrium may be displaced and a direct electron-transfer reaction may occur with production of ${ }^{*} \mathrm{NO}$ from $\mathrm{HNO}_{2}$. In this regard, one may note that polyphenols consumed in the diet (including flavonoids and phenolic acids) exhibit antioxidant activity largely supported by a reductive ability which, in turn, is highly dependent on their structure $[29,41]$. Therefore, these compounds are likely candidates to undergo a redox reaction with nitrite during digestion, yielding ${ }^{\bullet} \mathrm{NO}$. Accordingly, chlorogenic acid and quercetin (phenolics exhibiting a catechol moiety) were shown to enhance the production of $\cdot \mathrm{NO}$ from nitrite at acidic $\mathrm{pH}$ $[18,19]$. On the other hand, ascorbic acid, a compound that exhibits a low redox potential, and actively secreted in the stomach, has also been shown to be an efficient one-electron reductant of nitrite $[42,43]$.

Red wine has been attributed health promoting properties largely based on antioxidant properties of its high polyphenolic content [44]. Thus, considering the reductive activity of wine polyphenols it was tempting to look for a possible red winedependent ${ }^{*} \mathrm{NO}$ production from nitrite in the stomach. In vitro experiments were carried out to validate the hypothesis and to mechanistically address the nitrite-wine interaction. In addition, in vivo experiments in healthy volunteers confirmed the physiologic relevance of the process.

Accordingly, in vitro experiments (Fig. 1) show that red wine dose- and $\mathrm{pH}$-dependently promotes the formation of ${ }^{\bullet} \mathrm{NO}$ when mixed with nitrite. For a wine dilution in the range expected to be found in the stomach during a meal, up to $80 \%$ of nitrite is converted to ${ }^{\circ} \mathrm{NO}$ in a molar basis at $\mathrm{pH} 1.5$ (Fig. 1A, solid line 4). Considering that food intake increases the stomach $\mathrm{pH}$ it is shown that alkalinization (from 1.5 to 2.0 ) is associated with a decrease of the capacity of red wine to produce ${ }^{\circ} \mathrm{NO}$ (Fig. 1A).

To substantiate the production of $\cdot \mathrm{NO}$ promoted by wine from nitrite in vivo it is shown that the intake of red wine by human volunteers that had previously ingested a solution containing nitrate in proportions similar to those found in vegetables, resulted in the increased formation of ${ }^{\circ} \mathrm{NO}$, detected by chemiluminescence in the expelled air from stomach (Fig. 2). The ingestion of nitrate simulated the intake of nitratecontaining vegetables with the purpose to increase the availability of nitrite in the stomach $[24,25]$. Due to its content in polyphenols vegetables were not used to avoid competition reaction with polyphenols from red wine.

Overall, data suggest that the production of ${ }^{\circ} \mathrm{NO}$ is dependent on the phenolic $(\mathrm{Ph})$ content of red wine and involves the one-electron reduction of nitrite (in the form of $\left.\mathrm{HNO}_{2}\right)$ :

$$
\mathrm{Ph}-\mathrm{OH}+\mathrm{HNO}_{2} \rightarrow \mathrm{Ph}-\mathrm{O}^{\cdot}+{ }^{\cdot} \mathrm{NO}+\mathrm{H}_{2} \mathrm{O} .
$$

This conclusion is supported by the following observations: (1) Anthocyanin fraction obtained from red wine reproduces the effects of the original wine, as shown in Table 1. Quantitatively, the anthocyanin fraction closely mimics the effect of wine; (2) During the reaction of the wine with nitrite, simultaneously with $\cdot \mathrm{NO}$ formation, an EPR signal in the phenolic fraction is noticed (inset in Fig. 1B), thus pointing to a univalent redox interaction as the first step (3) a phenolic compound present in high quantities in red wine (for example in a Cabernet from 1998 its concentration was around $9 \mathrm{mg} / \mathrm{L} \mathrm{[45])} \mathrm{and} \mathrm{used} \mathrm{as} \mathrm{an} \mathrm{example} \mathrm{of} \mathrm{wine} \mathrm{catechol}$ reductant, caffeic acid, undergoes a redox transition with nitrite that involves the one-electron reduction product of nitrite, ${ }^{\circ} \mathrm{NO}$ (Fig. 3) and the corresponding one-electron oxidation product of the phenol, the caffeic acid $o$-semiquinone radical (Fig. 5A). Meaningful, the time courses of caffeic acid oxidation and ${ }^{\circ} \mathrm{NO}$ production coincide (inset Fig. 5C). The results with caffeic acid, 
as compared with those of $p$-coumaric acid, suggest that the reduction of nitrite by wine phenolics is highly dependent on the phenolic structure because, expectedly, the monophenol derivative of caffeic acid, $p$-coumaric acid, exhibiting a higher redox potential as compared with the catechol parent, was ineffective in promoting the reduction of nitrite to ${ }^{\circ} \mathrm{NO}$ (Fig. 3C).

Moreover, the spectral modifications of caffeic acid upon interaction with nitrite (Fig. 5B) are compatible with the reaction 6 proposed for the interaction, as the semiquinone radical may decay to the corresponding quinone by autoxidation or by a further interaction with nitrite.

To further substantiate the potential physiological impact of the wine phenolics in reducing nitrite we assayed caffeic acid in the presence of ascorbic acid (a compound which is secreted in the gastric juice and is able to reduce nitrite to ${ }^{-} \mathrm{NO}$ ). We showed that for the concentrations of nitrite and ascorbic acid compatible with an in vivo situation, the reductive effect of caffeic acid added to that of ascorbic acid (Fig. 4). This suggests that wine phenolics cooperate with ascorbic acid in the reduction of nitrite to $\mathrm{NO}$, providing enough nitrite is available.

It should be noted that the reduction of nitrite, encompassing the formation of the $o$-semiquinone radical and the corresponding o-quinone (Fig. 5), does not rule out other possible competition reactions, including nitrosation and nitration of the phenols. The quinone itself may undergo further reactions at low $\mathrm{pH}$, yielding polymeric products [46]. For instance, $\mathrm{N}_{2} \mathrm{O}_{3}$ formed via decomposition of $\mathrm{HNO}_{2}$ (reactions 2 and 3) can be used to nitrosate caffeic acid [47] and several other wine phenolics, including $p$-coumaric acid [48]. In fact, caffeic acid and its esters have been shown to be efficient inhibitors of nitrosation reactions $[46,49,60]$, thus acting as blockers of carcinogenic nitrosamines formation $[47,50,51]$. Several observations shown in this study suggest an interaction of caffeic acid with $\mathrm{NO}$ and NO-derived species, namely: the increase in the rate of $\cdot \mathrm{NO}$ decay with the increase of caffeic acid concentration (Fig. 3A), the spectral shift of the UV spectrum (Fig. 5B) and the increase of absorbance at $310 \mathrm{~nm}$ (Fig. 5C, line 3) for later times of reaction. The nitration of caffeic acid followed at $444 \mathrm{~nm}$ has also been observed before [60] in the presence of nitrite under acidic conditions but at such wavelength no appreciable spectral modifications were noticed in this study (Fig. 5B).

Moreover, the $o$-semiquinone radicals formed may undergo a free radical coupling with $\mathrm{NO}_{2}$ radical, yielding nitrated products, as has been shown for catecholic neurotransmitters [52]. The complexity of the mixture formed is further illustrated by the observation that the $\mathrm{NO}_{2}$ radical reacts fast with caffeic acid $\left(k=8.6 \times 10^{8} \mathrm{M}^{-1} . \mathrm{s}^{-1}\right)$ yielding the $o$-semiquinone radical [53]. However, this reaction is not likely to contribute in a great extent to the phenol radical formation in our experiments in view of the competition of $\mathrm{NO}_{2}$ radical with nitrite at microM level for caffeic acid and, also, because $\mathrm{HNO}_{2}$ used in reaction 2, spontaneously yielding $\mathrm{NO}_{2}$ radical, will be displaced by reaction 6 with caffeic acid.

During a meal the stomach acts like a chemical reactor, leading to the production of several different compounds which may exert local pathophysiological actions. The reduction of nitrite to ${ }^{\circ} \mathrm{NO}$ is particularly relevant due to the dual biological role of ${ }^{\bullet} \mathrm{NO}$ as a ubiquitous regulator involved in physiological processes or as a mediator of toxic processes. Therefore, the efficient reduction of nitrite by wine phenolics in the stomach shown here, increasing the bioavailability of $\cdot \mathrm{NO}$, may have strong pathophysiological impact. It has been proposed that the rapid rate of generation of $\cdot \mathrm{NO}$ at the gastric-esophageal junction will expose this region to a high local nitrosative stress witch may be involved in the high incidence of epithelial mutagenesis and cancer at this anatomical site [54,55]. On the other hand, beneficial effects include host defense against gut pathogens that have the capacity to survive in acidic medium [56] and regulation of gastric mucosal blood flow, increasing mucous thickness [57,58] and gastric motility [59]. Further considering that wine phenolics may compete for nitration and nitrosation reactions with other molecules during digestion avoiding the formation of toxic compounds (notably carcinogenic nitrosamines), the reduction of nitrite shown here may reveal health-promoting effects of red wine in connection with -NO bioactivity previously unrecognized.

\section{Acknowledgments}

This work was supported by FCT (Portugal) and FEDER, grant POCTI/AGR/42418/01. Bruno Gago is a PDBEB student (CNC) supported by fellowship SFRH/BD/15228/2004.

\section{References}

[1] Alderton, W. K.; Cooper, C. E.; Knowles, R. G. Nitric oxide synthases: structure, function and inhibition. Biochem. J. 357:593-615; 2001.

[2] Gladwin, M. T.; Schechter, A. N.; Kim-Shapiro, D. B.; Patel, R. P.; Hogg, N.; Shiva, S.; Cannon III, R. O.; Kelm, M.; Wink, D. A.; Espey, M. G.; Oldfield, E. H.; Pluta, R. M.; Freeman, B. A.; Lancaster Jr., J. R.; Feelisch, M.; Lundberg, J. O. The emerging biology of the nitrite anion. Nat. Chem. Biol. 1:308-314; 2005.

[3] Duranski, M. R.; Greer, J. J.; Dejam, A.; Jaganmohan, S.; Hogg, N.; Langston, W.; Patel, R. P.; Yet, S. F.; Wang, X.; Kevil, C. G.; Gladwin, M. T.; Lefer, D. J. Cytoprotective effects of nitrite during in vivo ischemiareperfusion of the heart and liver. J. Clin. Invest. 115:1232-1240; 2005.

[4] Webb, A.; Bond, R.; McLean, P.; Uppal, R.; Benjamin, N.; Ahluwalia, A. Reduction of nitrite to nitric oxide during ischemia protects against myocardial ischemia-reperfusion damage. Proc. Natl. Acad. Sci. U. S. A. 101:13683-13688; 2004.

[5] Zweier, J. L.; Wang, P.; Samouilov, A.; Kuppusamy, P. Enzymeindependent formation of nitric oxide in biological tissues. Nat. Med. 1:804-809; 1995.

[6] Bryan, N. S.; Fernandez, B. O.; Bauer, S. M.; Garcia-Saura, M. F.; Milsom, A. B.; Rassaf, T.; Maloney, R. E.; Bharti, A.; Rodriguez, J.; Feelisch, M. Nitrite is a signaling molecule and regulator of gene expression in mammalian tissues. Nat. Chem. Biol. 1:290-297; 2005.

[7] Weitzberg, E.; Lundberg, J. O. Nonenzymatic nitric oxide production in humans. Nitric Oxide 2:1-7; 1998.

[8] Suschek, C. V.; Schewe, T.; Sies, H.; Kroncke, K. D. Nitrite, a naturally occurring precursor of nitric oxide that acts like a 'prodrug'. Biol. Chem. 387:499-506; 2006.

[9] Bryan, N. S. Nitrite in nitric oxide biology: cause or consequence? A systems-based review. Free Radic. Biol. Med. 41:691-701; 2006.

[10] Spiegelhalder, B.; Eisenbrand, G.; Preussmann, R. Influence of dietary nitrate on nitrite content of human saliva: possible relevance to in vivo formation of N-nitroso compounds. Food Cosmet. Toxicol. 14:545-548; 1976. 
[11] Duncan, C.; Dougall, H.; Johnston, P.; Green, S.; Brogan, R.; Leifert, C.; Smith, L.; Golden, M.; Benjamin, N. Chemical generation of nitric oxide in the mouth from the enterosalivary circulation of dietary nitrate. Nat. Med. 1:546-551; 1995.

[12] Li, H.; Duncan, C.; Townend, J.; Killham, K.; Smith, L. M.; Johnston, P.; Dykhuizen, R.; Kelly, D.; Golden, M.; Benjamin, N.; Leifert, C. Nitratereducing bacteria on rat tongues. Appl. Environ. Microbiol. 63:924-930; 1997.

[13] Mowat, C.; Carswell, A.; Wirz, A.; McColl, K. E. Omeprazole and dietary nitrate independently affect levels of vitamin $\mathrm{C}$ and nitrite in gastric juice. Gastroenterology 116:813-822; 1999.

[14] Bartholomew, B.; Hill, M. J. The pharmacology of dietary nitrate and the origin of urinary nitrate. Food Chem. Toxicol. 22:789-795; 1984.

[15] Lundberg, J. O.; Weitzberg, E.; Cole, J. A.; Benjamin, N. Nitrate, bacteria and human health. Nat. Rev., Microbiol. 2:593-602; 2004.

[16] Moriya, A.; Grant, J.; Mowat, C.; Williams, C.; Carswell, A.; Preston, T.; Anderson, S.; Iijima, K.; McColl, K. E. In vitro studies indicate that acid catalysed generation of $\mathrm{N}$-nitrosocompounds from dietary nitrate will be maximal at the gastro-oesophageal junction and cardia. Scand. J. Gastroenterol. 37:253-261; 2002.

[17] Sobala, G. M.; Schorah, C. J.; Sanderson, M.; Dixon, M. F.; Tompkins, D. S.; Godwin, P.; Axon, A. T. Ascorbic acid in the human stomach. Gastroenterology 97:357-363; 1989.

[18] Takahama, U.; Oniki, T.; Hirota, S. Oxidation of quercetin by salivary components. Quercetin-dependent reduction of salivary nitrite under acidic conditions producing nitric oxide. J. Agric. Food Chem. 50:4317-4322; 2002.

[19] Peri, L.; Pietraforte, D.; Scorza, G.; Napolitano, A.; Fogliano, V.; Minetti, M. Apples increase nitric oxide production by human saliva at the acidic $\mathrm{pH}$ of the stomach: a new biological function for polyphenols with a catechol group? Free Radic. Biol. Med. 39:668-681; 2005.

[20] Teissedre, P. L.; Landrault, T. Wine phenolics: contribution to dietary intake and bioavailability. Food Res. Intern. 33:461-467; 2000.

[21] Serafini, M.; Laranjinha, J. A.; Almeida, L. M.; Maiani, G. Inhibition of human LDL lipid peroxidation by phenol-rich beverages and their impact on plasma total antioxidant capacity in humans. J. Nutr. Biochem. 11:585-590; 2000.

[22] Mattivi, F.; Zulian, C.; Nicolini, G.; Valenti, L. Wine, biodiversity, technology, and antioxidants. Ann. N. Y. Acad. Sci. 957:37-56; 2002.

[23] Wang, H.; Race, E. J.; Shrikhande, A. J. Characterization of anthocyanins in grape juices by ion trap liquid chromatography-mass spectrometry. J. Agric. Food Chem. 51:1839-1844; 2003.

[24] Lundberg, J. O.; Weitzberg, E.; Lundberg, J. M.; Alving, K. Intragastric nitric oxide production in humans: measurements in expelled air. Gut 35:1543-1546; 1994.

[25] Lundberg, J. O.; Govoni, M. Inorganic nitrate is a possible source for systemic generation of nitric oxide. Free Radic. Biol. Med. 37:395-400; 2004.

[26] Burton, D. D.; Kim, H. J.; Camilleri, M.; Stephens, D. A.; Mullan, B. P.; O'Connor, M. K.; Talley, N. J. Relationship of gastric emptying and volume changes after a solid meal in humans. Am. J. Physiol.: Gastrointest. Liver Physiol. 289:G261-G266; 2005.

[27] Geliebter, A.; Yahav, E. K.; Gluck, M. E.; Hashim, S. A. Gastric capacity, test meal intake, and appetitive hormones in binge eating disorder. Physiol. Behav. 81:735-740; 2004.

[28] Rossetto, M.; Vianello, F.; Rigo, A.; Vrhovsek, U.; Mattivi, F.; Scarpa, M. Stable free radicals as ubiquitous components of red wines. Free Radic. Res. 35:933-939; 2001.

[29] Laranjinha, J.; Almeida, L.; Madeira, V. Reduction of ferrylmyoglobin by dietary phenolic-acid derivatives of cinnamic acid. Free Radic. Biol. Med. 19:329-337; 1995.

[30] Muto, N.; Ohta, T.; Suzuki, T.; Itoh, N.; Tanaka, K. Evidence for the involvement of a muscarinic receptor in ascorbic acid secretion in the rat stomach. Biochem. Pharmacol. 53:553-559; 1997.

[31] Licht, W. R.; Tannenbaum, S. R.; Deen, W. M. Use of ascorbic acid to inhibit nitrosation: kinetic and mass transfer considerations for an in vitro system. Carcinogenesis 9:365-372; 1988.

[32] Mirvish, S. S. Inhibition by vitamins C and $\mathrm{E}$ of in vivo nitrosation and vitamin C occurrence in the stomach. Eur. J. Cancer Prev. 5 (Suppl. 1):131-136; 1996.

[33] Mowat, C.; McColl, K. E. Alterations in intragastric nitrite and vitamin C levels during acid inhibitory therapy. Best Pract. Res. Clin. Gastroenterol. 15:523-537; 2001.

[34] Laranjinha, J.; Cadenas, E. Redox cycles of caffeic acid, alpha-tocopherol, and ascorbate: implications for protection of low-density lipoproteins against oxidation. IUBMB Life 48:57-65; 1999.

[35] Benjamin, N.; O'Driscoll, F.; Dougall, H.; Duncan, C.; Smith, L.; Golden, M.; McKenzie, H. Stomach NO synthesis. Nature 368:502; 1994.

[36] McKnight, G. M.; Smith, L. M.; Drummond, R. S.; Duncan, C. W.; Golden, M.; Benjamin, N. Chemical synthesis of nitric oxide in the stomach from dietary nitrate in humans. Gut 40:211-214; 1997.

[37] Lundberg, J. O.; Carlsson, S.; Engstrand, L.; Morcos, E.; Wiklund, N. P.; Weitzberg, E. Urinary nitrite: more than a marker of infection. Urology 50:189-191; 1997.

[38] Weller, R.; Pattullo, S.; Smith, L.; Golden, M.; Ormerod, A.; Benjamin, N. Nitric oxide is generated on the skin surface by reduction of sweat nitrate. J. Invest. Dermatol. 107:327-331; 1996.

[39] Benjamin, N.; Pattullo, S.; Weller, R.; Smith, L.; Ormerod, A. Wound licking and nitric oxide. Lancet 349:1776; 1997.

[40] Lewis, R. S.; Tannenbaum, S. R.; Deen, W. M. Kinetics of N-nitrosation in oxygenated nitric-oxide solutions at physiological $\mathrm{Ph}$ - role of nitrous anhydride and effects of phosphate and chloride. J. Am. Chem. Soc. 117:3933-3939; 1995.

[41] Laranjinha, J. A. N.; Almeida, L. M.; Madeira, V. M. C. Reactivity of dietary phenolic-acids with peroxyl radicals - antioxidant activity upon low-densitylipoprotein peroxidation. Biochem. Pharmacol. 48:487-494; 1994.

[42] Mirvish, S. S.; Wallcave, L.; Eagen, M.; Shubik, P. Ascorbate-nitrite reaction: possible means of blocking the formation of carcinogenic Nnitroso compounds. Science 177:65-68; 1972.

[43] Archer, M. C.; Tannenbaum, S. R.; Fan, T. Y.; Weisman, M. Reaction of nitrite with ascorbate and its relation to nitrosamine formation. J. Natl. Cancer Inst. 54:1203-1205; 1975.

[44] Serafini, M.; Bugianesi, R.; Salucci, M.; Azzini, E.; Raguzzini, A.; Maiani, G. Effect of acute ingestion of fresh and stored lettuce (Lactuca sativa) on plasma total antioxidant capacity and antioxidant levels in human subjects. Br. J. Nutr. 88:615-623; 2002.

[45] Simonetti, P.; Gardana, C.; Pietta, P. Plasma levels of caffeic acid and antioxidant status after red wine intake. J. Agric. Food Chem. 49:5964-5968; 2001

[46] Cotelle, P.; Vezin, H. Reaction of caffeic acid derivatives with acidic nitrite. Tetrahedron Lett. 42:3303-3305; 2001.

[47] Kuenzig, W.; Chau, J.; Norkus, E.; Holowaschenko, H.; Newmark, H.; Mergens, W.; Conney, A. H. Caffeic and ferulic acid as blockers of nitrosamine formation. Carcinogenesis 5:309-313; 1984.

[48] Torres y Torres, J. L.; Rosazza, J. P. Reactions of p-coumaric acid with nitrite: product isolation and mechanism studies. J. Agric. Food Chem. 49:1486-1492; 2001.

[49] Napolitano, A.; d'Ischia, M. New insights into the acid-promoted reaction of caffeic acid and its esters with nitrite: decarboxylation drives chain nitrosation pathways toward novel oxime derivatives and oxidation/ fragmentation products thereof. J. Org. Chem. 67:803-810; 2002.

[50] Rao, A. V. Lycopene, tomatoes, and the prevention of coronary heart disease. Exp. Biol. Med. (Maywood) 227:908-913; 2002.

[51] Mirvish, S. S. Formation of N-nitroso compounds: chemistry, kinetics, and in vivo occurrence. Toxicol. Appl. Pharmacol. 31:325-351; 1975.

[52] Delabreteche, M. L.; Servy, C.; Lenfant, M.; Ducrocq, C. Nitration of catecholamines with nitrogen-oxides in mild conditions - a hypothesis for the reactivity of No in physiological systems. Tetrahedron Lett. 35:7231-7232; 1994.

[53] Zhouen, Z.; Side, Y.; Weizhen, L.; Wenfeng, W.; Yizun, J.; Nianyun, L. Mechanism of reaction of nitrogen dioxide radical with hydroxycinnamic acid derivatives: a pulse radiolysis study. Free Radic. Res. 29:13-16; 1998.

[54] Iijima, K.; Fyfe, V.; McColl, K. E. Studies of nitric oxide generation from salivary nitrite in human gastric juice. Scand. J. Gastroenterol. 38: $246-252 ; 2003$. 
[55] Crew, K. D.; Neugut, A. I. Epidemiology of gastric cancer. World J. Gastroenterol. 12:354-362; 2006.

[56] Dykhuizen, R. S.; Frazer, R.; Duncan, C.; Smith, C. C.; Golden, M.; Benjamin, N.; Leifert, C. Antimicrobial effect of acidified nitrite on gut pathogens: importance of dietary nitrate in host defense. Antimicrob. Agents Chemother. 40:1422-1425; 1996.

[57] Pique, J. M.; Whittle, B. J.; Esplugues, J. V. The vasodilator role of endogenous nitric oxide in the rat gastric microcirculation. Eur. J. Pharmacol. 174:293-296; 1989.
[58] Bjorne, H. H.; Petersson, J.; Phillipson, M.; Weitzberg, E.; Holm, L.; Lundberg, J. O. Nitrite in saliva increases gastric mucosal blood flow and mucus thickness. J. Clin. Invest. 113:106-114; 2004.

[59] Desai, K. M.; Sessa, W. C.; Vane, J. R. Involvement of nitric oxide in the reflex relaxation of the stomach to accommodate food or fluid. Nature 351:477-479; 1991.

[60] Kono, Y.; Shibata, H.; Kodama, Y.; Sawa, Y. The supression of the Nnitrosating reaction by chlorogenic acid. Biochem. J. 312:947-953; 1995. 